\title{
Socio-Demographic Characteristics of Parents and Emotional Burden on Discovery of Disabilities of their Children in a South African Community
}

\begin{abstract}
Objective: This study investigated the socio-demographic characteristics of parents of children with disabilities in a South African community. Also studied were their emotional responses.

Design and methodology: A social survey research and focus group designs were employed in this study to explore and describe parental emotions

Participants: 174 parents of children with disabilities were randomly selected and interviewed by this author and four research assistants at different locations in the Venda area of Limpopo Province of South Africa.
\end{abstract}

Results: Out of the 174 parents interviewed 95 (54.6\%) were parents of children with physical impairment (PCWPI), 51 (29.3\%) parents of children with hearing impairment (PCWHI) and 28 (16.1\%) were parents of children with visual impairment (PCWVI). Only 16 (9.2\%) of the parents interviewed had tertiary education with a majority (121 (or 69.5\%) of them unemployed. These unemployed parents solely relied on the monthly, government disability grant of R620 (or US\$89). Responses to grief, anger, shame were highest amongst PCWVI, while PCWPI were most worried (64.2\%) and demonstrated the highest percentage emotions of fear $(22.1 \%)$ and guilt $(221.1 \%)$. The following percentage of emotions were expresses by parents with formal tertiary education, anger (44\%), shame (37.5\%), disbelief (25\%), guilt (6.3\%), worry (50\%) and fear (25\%). While participants with the highest income (over R1800 or about US\$257), expressed the following percentage of emotions: grief (70.6\%), and disbelief (47.1\%).

Conclusion: Physiotherapist working with the disabled and their carers in the community within the concept of community based rehabilitation and social model of care would need to understand the characteristics and their emotional burden prior to assisting in creating an enabling environment and holistic empowering activities that would assist all.

\section{KEY WORDS: SOCIODEMOGRAPHIC CHARACTERISTICS, EMOTIONAL BURDEN}

\section{INTRODUCTION}

Family members develop certain expectations, wishes and desires during the course of the pregnancy. These dreams are abruptly terminated with the birth of a handicapped child (Bristor, 1984). According to Bristor (1984), the infant with impairment is a complete distortion of the dreamed-of and planned-for infant. Parental responses to the diagnosis of their child's chronic condition commonly include shock, disbelief, denial and anger (Austin, 1990; Canam, 1993; Eakes, 1995; Melnyk et al 2001).

Simon and Smith, (1992), reiterate that parents find it hard to accept a whole different child than what they had thought they were going to get. Parents are usually never prepared for this (Findings, 2003). A period of intense emotional upset (including sadness, anger, and anxiety) is followed by a period of gradual adaptation, which is marked by a lessening of intense anxiety and emotional reaction (Drotar et al 1975). Mothers share in the stigma and marginilisation of atypically developing offspring (McKeever and Miller, 2004).

Guilt is probably the most commonly invoked category of neurotic response within the psychodynamic interpretations. Indeed, guilt is seemingly unavoidable, because it can supposedly occur as either a cause or an effect of other emotions. Some parents believe that they are somehow responsible for their child's disability (Solnit and Stark 1961; Ferguson, 2002). The feeling of guilt, which arises during the grief stage may be intense. Parents feel that they are being punished for some past event. Parents whose children were older when the disability occurred may feel guilty over not recognizing the problem sooner or over not having been more tolerant and understanding towards the child. Guilt can lead to the parent's total dedication to the child (Fortier and Wanlass, 1984).

Grief may be time-limited (Kennedy, 1970; Hentinen and Kyngäs, 1998). Mourning may continue for a long time, it is periodic and seldom disappears and might be chronic (Olshansky, 1962; Mindel and Vernon, 1971; Wikler, et al 1981; Copley and Bodensteiner, 1987; Milo 1997) or postponed (Frued, 1924). Most parents achieve partial resolution

\section{CORRESPONDENCE TO: \\ Dr U Useh}

Physiotherapy Department,

University of Limpopo,

MEDUNSA Campus

P.O. Box 239

Medunsa 0204

South Africa

Email: efeuseh@yahoo.com or uuseh@medunsa.ac.za 
of this painful emotion (Fortier and Wanlass, 1984, Aitken et al, 2004). Drench (2003) stressed that, loss, grief, and adjustment are parts of a continuum rather than a linear progression with finite points. The grief stage is characterized by feelings of anger, guilt and sadness. Putting them in contact with others having similarly diagnosed children may help counteract the feelings of being different and isolated from society (Fortier and Wanlass, 1984). Parents sometimes reach a point that they are angry with the disabled child for disrupting the family routine and causing great stress within the system (Epperson, 1977).

Anger can be expressed in various forms such as displacement, passive aggression and isolation. Parents may avoid other parents with normal children because they feel anger and questions their ability to handle this anger (Fortier and Wanlass, 1984). Since many parents have had no previous experience with major physical disability, they are unprepared for dealing with them. They are angry because they seem to have been singled out by fate (Cohen, 1962). Anger was expressed in many ways. It may take the form of self-pity. In most cases the anger is directed towards themselves, the baby or outwardly towards hospital staff and other people. Before parents can master their feelings sufficiently to be able to accept the fact that their child has any form of impairment, they are placed under considerable stress (McCubbin et al. 1983). Their patterns of adaptation, both individually and within the family may be severely strained. The child's impairment often triggers personal anxieties and re-opening of old wounds. In certain instances the parent view their child's handicap as a punishment for some imagined or real behaviour on his/her own part, which he/she felt was bad (Cohen, 1962). Cohen (1993), further stressed that when there is a child with impairment in the home, the entire manner in which the family has lived may have to be changed. Parents become involved not only in arranging for the child to have medical treatment but also in instituting a regimen of other forms of therapy and physiotherapy. The effect of this on parental well being can not be ignored (Jansen et al, 2003).

The psychological effects of maladaptation and the dysfunctional aspect of a family coping and adjusting to chronic illness such as anxiety depression and marital discord has been documented (Lawler et al, 1966, Spock and Stedman, 1966; Tropauer et al, 1970; and McCubbin et al, 1983, Pain 1999; McKeever and Miller, 2004). However, a dearth of information on the South African situation was observed. This study investigated the demographic characteristics of parents of children with disabilities (CWD) in Venda area of the Limpopo Province of South Africa. This study also explored and described their emotions on discovery of child's disability. The Venda people are found in the Northern region (Vhembe district) of the Limpopo Province of South Africa. Vhembe shares her northern and northwestern borders with Zimbabwe and Botswana respectively; western and eastern borders with Makhado (Louis Trichardt) and the Kruger National Park respectively (Becker, 1979).

The census 2001 statistics indicated that Vhembe Municipality has a total population of 1199885 ; with 1181672 (98.5\%) people of African descent, 1658 $(0.14 \%)$ coloureds, $2928(0.24 \%)$ Indians and $13627(1.1 \%)$ whites (Demarcation, 2003). According to Demarcation (2003), the census of 2001 also reveals the distribution of the highest education levels attained by over 20 year olds as follows: Persons with no formal education as 180485 (15\%); some primary education, 75094 (6.3\%); completed primary school were $32522(2.7 \%)$ persons, secondary education, 151882 (12.5\%); grade $12,80760(6.7 \%)$ persons and those with tertiary education were only $41708(3.5 \%)$ persons. The individual monthly income statistics revealed that $881737(73.5 \%)$ persons had no form of income while only $130(0.01 \%)$ persons had a monthly income of over R 200,000. The dominant impairments were visual (sight) (13710 (1.14\%) persons), physical (10810 (0.9\%) persons) and hearing (9688 $(0.8 \%)$ persons).

This study is delimited to parents of children with physical impairment (PCWPI), parents of children with visual impairment (PCWVI), and parents of children with hearing impairment (PCWHI) who were attending a special school in Thohoyandou, Limpopo Province, South Africa. The children will collectively be referred to as children with disabilities (CWD).

\section{Theoretical and philosophical framework}

We live in a rapidly evolving world in which social, educational, economic and political contexts are ever changing faster. The constructs of social justice, democratisation and globalisation have contributed to the breaking down of barriers and the creation of inclusionary practices in a variety of contexts (Eloff, et al, 2002). The philosophical credo of parental emotion to children with disabilities is premised on the belief that parents are often discriminated against and excluded by proxy from societal activities and facilities. Parents' emotions to their CWD (regardless of their socioeconomic status, cultural origin, religion or the nature of the physical disability of the child) are influenced by the societal perception. Attitudes towards disability and research about disability have changed over the years. The sociology of disability was part of this development (Abberley, 1987). Traditional approaches to disability have depicted disability and the medical model as a health and welfare issue, to be addressed through care provided to persons with disabilities in the form of charitable handouts and similar measures and management of their tragedies (French and Swain, 2004). As a consequence, persons with disabilities and their families have been marginalized and excluded both from the mainstream of society and have been denied, or significantly limited in the enjoyment of their fundamental human rights and freedom (United Nations, 2003). The definition of disability by the WHO in 1980 reflects a medical model (WHO, 1980). In recent years, however, a broader understanding of disability, namely the 'social model', has superseded this approach (WHO, 1999; WHA, 2001). Careful consideration should therefore be given to carers and parents of children with disabilities in the bio-psychosocial model of care. 


\section{METHODS}

\section{Design, participants and setting}

The data presented here is part of a larger study that investigated the attitudes of parents to children with disability amongst the Venda people in the Limpopo Province of South Africa.

\section{Design}

A social survey research and focus group designs were employed in this study to explore and describe parental emotions.

\section{Participants}

Participants in this study were systematically sampled from the school's register (which was the sampling frame) with a sampling interval or $\mathrm{k}$ equals to two. In addition to learners with other disabilities, the school has 363 children with physical disabilities that met the criteria for this study. There were 200 with physical impairments; 105 with hearing impairments and 58 with visual impairments. Each group of impairment was systematically sampled with kth equals to 2. The sample size became 100, 53 and 29 children with physical, hearing and visual impairments respectively. The sample was not matched according to gender or age of children but randomized by their impairments in order to provide three different homogenous grouping of the respondents to control intrinsic subject characteristics. Out of the initial sample size of 182 parents, 174 (95 of them were PCWPI, 51 were PCWHI and 28 were PCWVI) parents showed interest in the study after 13 parents (fathers) later dropped out of the study because they were working in other Provinces and could not make the appointments. According to Krejcie and Morgan's (1970), the sample size for a population of 320 should be 175 . Therefore, with due consideration for homogeneity of the target population and the sampling technique used in this study, the sample size of 174 parents was judged to be representative (Polit and Hungler 1991; Leedy, 1997; Neuman, 1997).

\section{Design of the interview schedule}

The contents of the interview schedule were developed through focus group discussions with parents of CWD. Information obtained also supplemented data gathered from the survey which also provided insight into the factors that influenced parents' emotion. A moderator (author) and an assistant moderator conducted the focus groups. The assistant moderator was a parent of a CWD and an MPhil student in a disability studies programme in South Africa. The content of the focus group was recorded with an audiotape and later transcribed verbatim. Ten parents of CWD were purposively chosen to participate in the focus group discussion with 7 agreeing to participate. Two of the participants were PCWVI; 3 were PCWPI, and the other two were PCWHI. A structured interview guide was used to direct the flow of the conversation. The main topic of the focus group discussion was on the emotions and experiences of parents on discovery of child's disability. The first focus group discussion was held on the 30th of April 2003 at the school premises. Parents and the author agreed that another focus group discussion be held but this time outside the school premises. Parents indicated that they would discuss the topic more freely if the group met outside the school premises. To minimize the influence of external factors such as situational contaminants, therefore the second focus group was therefore held on the 16th of May 2003 at the residence of one of the parents.

\section{The interview schedule}

The structured interview schedule used in this study consisted of mixture of standardized sets of closed ended questions to ensure some level of quantification and open-ended questions to provide more in-depth information. The interview schedule comprises four sections A to D. Section A provides demographic information of the child, $\mathrm{B}$ parental information, $\mathrm{C}$ health information, D parental emotions on discovery of child's disability.

A pilot study was done to test the questions for reliability. The correlation coefficient on inter-rater reliability was 0.85 .

The five subjects who participated in the pilot study were excluded from the final study. Participants were requested to comment on the content of the final interview schedule to control content validity. The pretest produced meaningful suggestions, which precipitated changes to the final schedule that was used to collect data.

\section{Research assistants}

Four post graduate university students (one of them was also a parent of a CWD) acted as research assistants. They were all residents within the area of study. During the training workshop, the cultural sensitivity and suitability of the instrument were discussed and the instrument was modified accordingly. The research assistants were required to translate the structured interview independently. An independent auditor (who was fluent in both English and Tshivenda (Venda language)) was required to verify the authenticity of their translation. The front and back translation (from English to Venda and vice versa) by each assistant was verified one at a time and privately so that they could not influence one another. The purpose of this translation was to ensure that the Venda- speaking research assistants had a similar understanding of the interview schedule and that the use of Venda during the interview process would not change the meaning of the questions thus affecting interpretations.

\section{Procedure for data collection}

After the pilot study, parents of the selected children were followed up through the contact information that was provided by school authorities. Interviews were carried out after informed consent was obtained. All interviews took place at the homes of the parents. Each interview lasted about fifty minutes. Questions were read verbatim to ensure standardization and simple probing was done when necessary to obtain additional and more clarifying information.

\section{Data Analysis}

The responses obtained from the structured interview were quantitatively analysed with the help of the Statistical Package for the Social Sciences, (SPSS) Windows 12.0 version. The descriptive statistics of percentages, frequency tables on various parameters and distribution along standard demographic lines (gender, age, socio-economic status and education) were compiled to make results clear and meaningful. 
To analyse the result of the focus group discussion, preliminary analysis began in debriefing session between the moderator and assistant moderator immediately after each focus group. All audiotaped focus group session were fully transcribed into narrative written form. The moderator coded the data using theoretical construct. A colleague who is also a qualitative researcher assisted with the coding and analysis of the data. Analysis was terminated when theoretic saturation was reached. Results of the thematic analysis were sent to participants to review and comment. The patterns in the data provided detailed description of parental emotions to CWD.

\section{RESULTS}

Out of the 174 parents interviewed, 95 (54.6\%) were PCWPI, 51 (29.3\%) were PCWHI and $28(16.1 \%)$ were PCWVI. One hundred and fifty eight, $(91 \%)$ of the parents were women while $16(9 \%)$ were men. Their age ranged between 21 and 78 years.

\section{Socio-economic status of the parents}

Only $16(9.2 \%)$ of the parents interviewed had tertiary education with a majority (121 (or 69.5\%) of them unemployed. These unemployed parents solely relied on the monthly, government disability grant of R620 (about
US\$89). The socio-economic status of the parents is presented in Figure 1.

Parents emotion on discovery of child's disability

Apart from the responses to guilt and disbelief, the overall affirmative responses across all emotion on discovery of child's disability were quite high (Table 1). Emotional responses of fear were found to be generally low except for those by PCWHI (52\%).

\section{Reasons for emotional reactions}

Parents also expressed sadness, emotional pain and shame from comments and attitudes within the family, stares and comments from the members of the society. The is supported by the following dialogue from four parents $(\mathrm{P} 1, \mathrm{P} 2$, $\mathrm{P} 3$, in the focus group:

P1 "I was so shy, ashamed and scared .., because, long ago these children (with disabilities) used to be killed".

P1 "They were used to be killed by the grannies"

P3 "I was worried... When I see my own, who cannot do anything"

Parents emotions by nature of disability (NOD)

Responses to grief, anger, shame were high amongst PCWVI, while PCWPI were most worried (64.2\%) and demonstrated the highest percentage emotions of fear (52\%) and guilt (22.1\%) (Table 1).
Parents emotion by educational status

Parents with formal tertiary education expressed low percentage of all emotions (except grief); anger (44\%), shame (37.5\%), disbelief $(25 \%)$, guilt $(6.3 \%)$, worry (50\%) and fear (25\%) (Table1).

\section{Parents emotion by income}

Participants with the highest income (over R1800 or about US\$257), expressed the high percentage of grief (70.6\%), and disbelief (47.1\%). Only $5.9 \%$ of the parents were also found to express guilt and while $24 \%$ were afraid on discovery of child's disability (Table 1).

\section{DISCUSSIONS}

This study described and explored the socio-demographic characteristics and the different emotions expressed by parents on discovery of their child's disability. The low level of formal education amongst parents in general and women in particular in this study was found to be quite high. The outcome of this study was similar to those recorded by the Department of Social Welfare (1997); Rambiyana and Kok (2002); and Demarcation (2003). The high level of unemployment and hence dependence on disability grant perpetuates the cycle of poverty amongst disabled families. Demarcation (2003), reports that about 900,000 persons (or $73 \%$ of the total population) in the Limpopo Province

\section{Figure 1: Socio-economic status of parents interviewed}

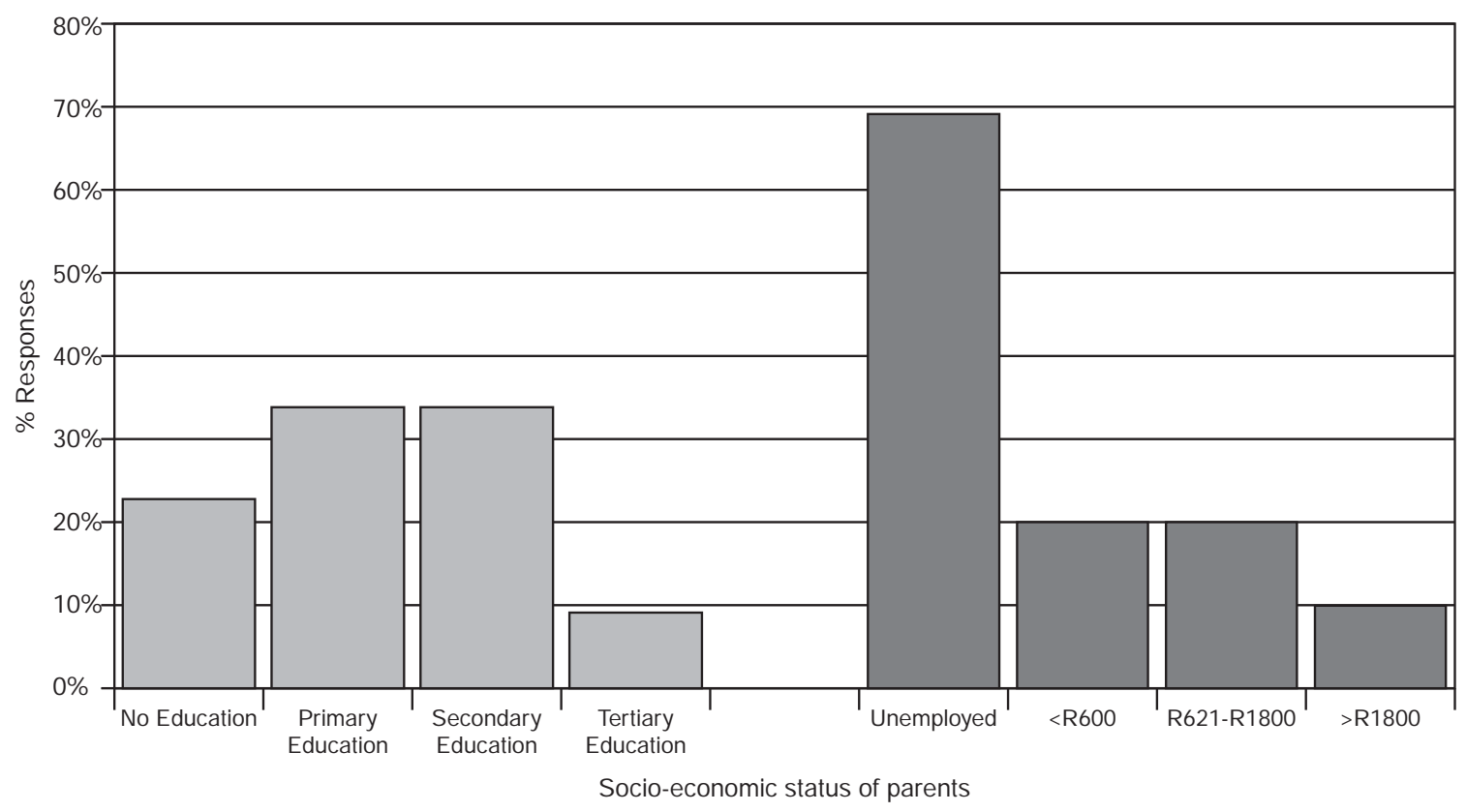


had no form of income. According to UNDP (1997), and the Department of Social Welfare (1997), 1,6\% of the total South African population receives disability grant. The provinces of Limpopo, Eastern Cape and KwaZulu- Natal with the lowest socio-economic indicators have the largest number of beneficiaries of disability grants. The high unemployment rate coupled with limited facilities for people with disabilities makes the situation cyclical. According to Swain (2004) disability creates and exacerbates poverty by increasing isolation and economic strain not just for the individual but for the family: there is little doubt that disabled people are amongst the poorest people in poor countries.

Physiotherapist working with the disabled in the community within the concept of community based rehabilitation should assist in creating empowering activities that would assist all parents of CWD. For example, physiotherapists can encourage parents of disabled children to be more involved in fora where they can influence the development of relevant services such as accessible environment, appropriate transport and communication methods. According to French (2005), within the perspective of social model of disability, professional power can be used to highlight the shortfall in resources for disabled people to ensure that the subjugated voices of the disabled people are heard and responded to, and to encourage and support disabled people to assert themselves so that their expertise about disability is at the centre of services and support.

To be able to fully use our professional power we need to understand what influences parental responses to their children disability.

\section{General emotional responses on dis- covery of child's disability}

The emotional reactions demonstrated by parents in this study are similar to those of previous studies (Strauss \& Munton 1985; Leifson 1987; Austin 1990; Clubb 1991; Simon \& Smith 1992; Canam 1993; Eakes 1995; Tanner et al. 1998; Melnyk et al. 2001; Poorten and Louw 2002; Findings 2003; Aitken et al 2004). According to Boushey (2001), you are angry at the world, yourself, your spouse, perhaps even at God. A low percentage of disbelief and guilt was however found amongst parents (Table 1). This concurs with those of Melnyk et al. (2001). Parents often indicated that they were not responsible for their child's physical disability. This might also be connected to the belief amongst most Africans who indicated that illness and diseases are externally created and that they can do nothing about it.

\section{Emotional responses by nature of dis- ability}

It is not very clear why PCWVI experienced such high levels of grief, anger and shame. The most probable reason may be that a few of the children with visual impairment (CWVI), in this study also had albinism. The burden of managing the double impairment of skin and sight, in addition to the societal prejudices and stigma associated with albinism might have contributed to the parental expression of grief, anger and shame. According to Lund and Gaigher (2002), in African communities, where traditional explanations concentrate on the misfortune of illness or deviance rather than on a biomedical explanation of it physical causes, such 'deviant' appearances can impact negatively on the socialization of the CWD. Kromberg and Jenkins (1982) had previously reported that the source of great anguish and shame to parents is associated with the stigma associated with albinism. Another possible factor that might have influenced the emotion of the PCWVI and PCWPI might also be the visibility of the nature of the disability or impairment. According to Safilios-Rothschild (1982), the degree of prejudice directed towards the sick and the disabled, seems to be influenced by a number of interrelated factors amongst which is the

Table 1: Parents emotions on discovery of child's disability

\begin{tabular}{|c|c|c|c|c|c|c|c|c|c|c|c|c|c|c|}
\hline \multirow[t]{2}{*}{ Variables } & \multicolumn{2}{|c|}{ Grief } & \multicolumn{2}{|c|}{ Anger } & \multicolumn{2}{|c|}{ Shame } & \multicolumn{2}{|c|}{ Disbelief } & \multicolumn{2}{|c|}{ Guilt } & \multicolumn{2}{|c|}{ Worry } & \multicolumn{2}{|c|}{ Fear } \\
\hline & $\mathbf{N}$ & $\%$ & $\mathbf{N}$ & $\%$ & $\mathbf{N}$ & $\%$ & $\mathbf{N}$ & $\%$ & $\mathbf{N}$ & $\%$ & $\mathbf{N}$ & $\%$ & $\mathbf{N}$ & $\%$ \\
\hline \multicolumn{15}{|l|}{ NOD } \\
\hline Physical & 54 & 56.8 & 54 & 57 & 49 & 51.6 & 34 & 35.8 & 21 & 22.1 & 61 & 64.2 & 49 & 52 \\
\hline Hearing & 48 & 78.4 & 32 & 73 & 32 & 62.7 & 24 & 47.1 & 2 & 4 & 26 & 51 & 9 & 18 \\
\hline Visual & 23 & 82.1 & 21 & 75 & 19 & 67.9 & 9 & 32.1 & 4 & 14.3 & 14 & 50 & 8 & 29 \\
\hline \multicolumn{15}{|l|}{$\begin{array}{l}\text { Parental } \\
\text { Education }\end{array}$} \\
\hline None & 24 & 60 & 20 & 50 & 24 & 60 & 16 & 40 & 7 & 17.5 & 21 & 52.5 & 14 & 35 \\
\hline Primary & 43 & 72.8 & 45 & 76 & 37 & 62.7 & 26 & 44.1 & 9 & 15.3 & 37 & 62.7 & 18 & 31 \\
\hline Secondary & 40 & 67.7 & 35 & 59 & 33 & 56 & 21 & 35.6 & 10 & 17 & 35 & 59.3 & 30 & 51 \\
\hline Tertiary & 10 & 62.2 & 7 & 44 & 6 & 37.5 & 4 & 25 & 1 & 6.3 & 8 & 50 & 4 & 25 \\
\hline \multicolumn{15}{|l|}{ Parents' income } \\
\hline Less than R620 & 12 & 66.7 & 12 & 67 & 8 & 44.4 & 5 & 27.8 & 2 & 11.1 & 10 & 55.6 & 10 & 56 \\
\hline $\mathrm{R} 620$ & 81 & 66.9 & 75 & 62 & 68 & 56.2 & 48 & 39.7 & 22 & 18.2 & 72 & 59.5 & 47 & 39 \\
\hline R621-1800 & 12 & 66.7 & 11 & 61 & 14 & 77.8 & 6 & 33.3 & 2 & 11.1 & 9 & 50 & 5 & 28 \\
\hline Over R1800 & 12 & 70.6 & 9 & 53 & 10 & 58.8 & 8 & 47.1 & 1 & 5.9 & 10 & 58.8 & 4 & 24 \\
\hline
\end{tabular}


visibility of the illness or disability. This assertion is supported by Kromberg et al. (1987), who reported that parents of children with defects that are visible are more anxious and withdrawn than others. The immediate shock of the confirmation of the presence of a visible physical impairment, and the reality of the metaphoric death or loss of the ideal, dreamed of and the wished for child might be responsible for the high percentage expression of grief, anger and shame (Fortier and Wanlass 1984). Similar findings had been previously documented by Bristor (1984); Milo (1997) and Tanner et al. (1998).

Income and educational status and responses

The percent responses by parents with the highest level of formal education were low on disbelief, guilt, shame, worry and fear. This agrees with the findings of Hentinen and Kyng\%os (1998), who indicated that parents with adequate personal and social resources and higher education adapted better than those with poor resources and a lower level of education and income. They also reiterated that, in order to adapt to a child's chronic condition, parents need time and resources.

While the emotional responses of parents with primary education to grief $(72.8 \%)$, anger $(76 \%)$, shame $(62.7 \%)$, disbelief $(44.1 \%)$ and worry $(72.7 \%)$ were quite high (Table1). The highest percentage of guilt $(17.5 \%)$ and fear $(35 \%)$ were expressed by parents with no formal education. The differences in emotional burden and responses to the discovery of $\mathrm{CD}$ according to parental education may be influenced by the fact that least educated parents are most vulnerable to societal prejudices and discrimination by the community. These are also the parents who would be most likely influenced by (or even believe in) societal myths and taboos with regard to causes of childhood disability, hence the fear and guilt. These groups of parents should therefore be targeted for specific disability education and support by physiotherapists and other members of the rehabilitation team.

Parents who participated in this study were from one school with a majority from Venda ethnic group. It is possible that participants emotions might have been influenced by their different culture, tradition and different belief systems and therefore, the findings of this survey can only be generalized to the Venda population of parents of CWD attending the special school. A larger study is recommended to include parents of CWD in other groups so that the findings could be generalised to a larger population. Another possible limitation is that the majority of the respondents were women, therefore the emotions generated here might also have a gender bias.

\section{CONCLUSION}

Parents' emotions were found to be influenced by their levels of formal education, income and the nature of the child's disability (CD). Parents with higher levels of education and income were found to present less severe emotional responses on discovery of child's disability. These categories of parents would therefore be able to create an enabling environment and openly participate in the care of their CWD without societal intimidation and prejudices if given adequate support. Physiotherapists therefore should make conscious effort and decision to heighten their awareness of disability and its effect on patients and carers so that they would be able to provide support and more effective in community based rehabilitation practice with emphasis on social model of care.

\section{REFERENCES}

Abberley P 1987 The concept of oppression and the development of a social theory of disability. Disability, Handicap \& Society 2:5-19.

Aitken EM, Mele N, Barrett KW 2004 Recovery of injured children: parent perspectives on family needs. Arch Phys Med Rehabilitation 85: 567-573.

Austin J 1990 Assessment of coping mechanisms used by parents and children with chronic illness. Maternal Child Nursing. 15 : 98-102.

Becker, P 1979. Inland tribes of South Africa, pp125. Granada publishing limited, London.

Boushey A 2001 The grief cycle; one parent's trip around. Focus on Autism and Other Developmental Disabilities 16: 7-30.
Bristor MW 1984 The Birth of a Handicapped child; a holistic model for grieving. Family relations. 33:25-32.

Canam C 1993. Common adaptive task facing parents of children with chronic conditions. Journal of Advanced Nursing. 18: 46-53.

Clubb RL 1991 Chronic Sorrow: adaptation patterns of parents with chronically ill children Pediatric Nursing 17: 461-466.

Cohen P 1962 The impact of a handicapped child on the family. Social Casework 43: 137-142.

Cohen MH 1993 The unknown and the unknowable: managing sustained uncertainty. Western Journal of Nursing Research 15: 77-96.

Copley M, Bodensteiner J, 1987 Chronic sorrows in families of disabled children. Journal of Child Neurology 2:67-70.

Demarcation 2003. Demographics of Thohoyandou. Available at: http://www.demarcation.org.za/ demarcprocess/.../plcnameDemog.asp? placename $=$ Thohoyando $(11 / 5 / 03)$

Department of Social Welfare 1997. White paper for social welfare, principles, guidelines, recommendations, proposed policies and programmes for developmental social welfare in South Africa. Pretoria: Government Press.

Drench, ME 2003. Loss grief and adjustment: a primer for physical therapy, parts $1 \& 2$. Available at: http://www.apta.org/Education/ Continuinf_Education/onLine_ceu_List/Loss _Grief/intro

Drench ME 2003 Loss grief and adjustment: a primer for physical therapy, parts $1 \& 2$. Available at: http://www.apta.org/Education/ Continuinf_Education/onLine_ceu_List/Loss _Grief/intro

Drotar D, Baskiewicz A, Irvin NI, Kennell J, Klaus M, 1975 The adaptation of parents to the birth of an infant with a congenital malformation: a hypothetical model. Pediatrics 56:710-717

Eakes G 1995 Chronic sorrow: the lived experience of parents of the chronically mentally ill. Archives of Psychiatric Nursing. 9:77-84.

Eloff I, Swart E, Engelbrecht P 2002 Including a learner with physical disabilities: stressful for teachers? Koers 671: 77-99. 
Epperson M 1977 Family is sudden crisis. Social work in Health Care 2: 265-273.

Ferguson PM 2002 A place in the family: an historical interpretation of research on parental reactions to having a child with a disability. The Journal of Special Education 36:124-130.

Findings 2003. The impact of childhood disability on family life. Available at: http://www.jrf.org.uk/knowledge/findings/soc ialcare/631.asp.23/o1/16.

Fortier LM, Wanlass RL, 1984 Family crisis following the diagnosis of a handicapped child. Family Relations 33:13-24.

French S 2005 Defining disability: implications for physiotherapy practice. In: French S, Sim J (eds). Physiotherapy: a psychosocial approach, pp 272. Elsevier, London

French S, Swain J, 2004. Whose tragedy? Towards a personal non-tragedy view of disability. In :Swain J, French S, Colin Barnes, Thomas C (eds). Disabling Barriers - Enabling Environments, pp 34-40. Sage in Association with the Open University Press, London.

Freud S 1924. Mourning and Melancholia: in collected papers. New York: Basic Books.

Hentinen M, Kyng\%os H 1998 Factors associated with the adaptation of parents with a chronically ill child. Journal of Clinical Nursing 7:316-324.

Jansen LMC, Ketelaar M, Vermeer A, 2003 Parental experience of participation in physical therapy for children with physical disabilities. Developmental Medicine \& Child Neurology 45 :58-69.

Kennedy J 1970 Maternal reactions to birth of a defective baby. Social Casework 51: 410416.

Krejcie R V, Morgan DW, 1970 Determining sample size for research activities. Educational and Psychological Measurement 30: 607-610

Kromberg JGR, Jenkins T, 1982 Prevalence of albinism in Southern Negro.

South African Medical Journal 61:383-386.

Kromberg JGR, Zwane EM, Jenkins T 1987 The response of black mothers to the birth of an albino infant. American Journal of Diseases of Children (AJDC)141:911-915.

Lawler RH, Nakielny W, Wright NA, 1966 Psychological implications of cystic fibrosis. Canadian Medical Journal 94:1043-1046.

Leedy PD 1997. Practical research; planning and design pp210; 6th edn. Prentice-Hall International Limited, London.
Leifson J 1987 Assessing families of infants with congenital defects. In: Wright L LeabeyM (eds.) Family and chronic illness, pp102. Spring house Corporation, Springhouse, $\mathrm{Pa}$.

Lund PM, Gaigher R, 2002 A health intervention programme for children with albinism at a special school in South Africa. Health Education Research 17:365-372.

McCubbin HI, McCubbin MA, Patterson JM, Cauble AE, Wilson LK, Warwick W, 1983 CHIP - Coping health inventory for parents: an assessment of parental coping patterns in the care of the chronically ill child. Journal of Marriage and Family 45:359-370.

Mc.Keever P, Miller K, 2004. Mothering children who have disabilities: a Bourdieusian interpretation of maternal practices. Social Science \& Medicine. 59: 1177-1191.

Melnyk MB, Feinstein F, Moldenhouer Z, Small L, 2001 Coping in parents of children who are chronically ill: strategies for assessment and intervention. Pediatric Nursing, 27: 547-557.

Milo EM 1997 Maternal responses to the life and death of a child with a developmental disability: a story of hope. Death Studies. 21: 443-476.

Mindel E, Vernon M, 1971 They grow in silence. The deaf child and his family. Silver spring. M.D: National Association of the Deaf

Neuman WL 1997 Social research methods: qualitative and quantitative approaches, 3rd edn. pp 221 Boston : Allyn \& Bacon.

Olshansky S 1962 Chronic sorrow: a response to having a mentally defective child. Social Casework. 43: 190-194.

Pain H 1999 Coping with a child with disabilities from the parents' perspective: the function of information. Child: Care and Development. 25:299-312.

Polit DF, Hungler BP, 1991 Nursing research; principles and methods; 4th edn. pp 265. Philadelphia: J.B. Lippincott Company.

Poorten LT, Louw B, 2002. Mothers' experiences when their infants were diagnosed with cleft lips and/ or palates. Health SA Gesondheid 7:2:56-67.

Rambiyana NG, Kok JC, 2002 Parents' expectations of public schooling in the Northern Province of South Africa. South African Journal of Education 22: 10-14.

Safilios-Rothschild, C 1982 Disabled person's self-definitions and their implications for rehabilitation. In Albrecht GL (ed) The sociology of Physical disability and rehabilitation, pp39-56. Feffer and Simon Inc., London.
Simon NB, Smith A, 1992. Living with chronic pediatric liver disease: the parent's experience. Pediatric Nursing 18: 453-489.

Solnit A, Stark M 1961 Mourning the birth of a defective child. The psychoanalytic study of the child 16: 523-527.

Spock A, Stedman D, 1966 Psychologic characteristics of children with cystic fibrosis. North Carolina Medical Journal 27:426-428.

Strauss SS, Munton M, 1985 Common concerns of parents with disabled children. Pediatric Nursing 11: 371-375.

Swain J 2004 International perspectives on disability. In: Swain J, French S, Colin B and Thomas C (eds) Disabling Barriers - Enabling Environments, pp54-60.Sage in Association with the Open University Press, London

Tanner JL, Dechert MP, Frienden IJ, 1998 Growing up with a facial hemagioma: Parent and child coping and adaptation. Pediatrics 101: 446-452.

Tropauer A, Franz, MN, Dilgard VW, 1970. Psychological aspects of the care of children with cystic fibrosis. American Journal of Diseases of children199: 424-432.

United Nations 2003. Evolution of thinking about disability issues-a human rights approach. International Norms and Standard 2/8. Available at: http://www.un.org/esa/ sodev/enable/disberk2.htm

United Nations Development Programme (UNDP) 1997. Human development report 1997. Oxford University Press, Oxford.

Wikler L, Wasow M, Hatfield E 1981 Chronic sorrow revisited: parent vs. professional depiction of the adjustment of parents of mentally retarded children. American Journal of Orthopsychiatry 51: 63-70.

World Health Assembly (WHA) 2001 International classification of functioning, disability and health, fifty-fourth World Health Assembly. Ninth plenary meeting A54/VR/9.

World Health Organization 1980 International Classification of Impairments, Disabilities, and Handicaps pp47. WHO, Geneva.

World Health Organization 1999. International Classification of Impairment Activities and participation. WHO, Geneva. 